\title{
PEMBINAAN EKONOMI KREATIF DALAM PERSPEKTIF PENDIDIKAN EKONOMI
}

\author{
Muhammad Hasan \\ Pendidikan Ekonomi Universitas Negeri Makassar \\ Email: m.hasan@unm.ac.id
}

\begin{abstract}
This study aims to determine the effect of entrepreneurial knowledge on the creative attitude of SMEs in the sub-sector of creative economy in Kecamatan Panakkukang in the context of creative economy development. The population in this research is 129 SMEs sub-sector of creative industry. Total samples in this study were 33 samples. The results of this study showed that entrepreneurial knowledge has a positive and significant influence on the creative attitude of SMEs in creative economy sub-sector in Kecamatan Panakkukang Makassar.
\end{abstract}

Keywords: Entrepreneurial knowledge, creative attitude, creative economy, economic education

\begin{abstract}
Abstrak: Penelitian ini bertujuan untuk mengetahui pengaruh pengetahuan kewirausahaan terhadap sikap kreatif pelaku UMKM subsektor ekonomi kreatif di Kecamatan Panakkukang dalam konteks pembinaan ekonomi kreatif. Populasi dalam penelitian ini adalah 129 pelaku UMKM subsektor industri kreatif. Total sampel dalam penelitian ini adalah sebanyak 33 pelaku UMKM subsektor industri kreatif. Hasil penelitian ini menunjukan pengetahuan kewirausahaan mempunyai pengaruh yang positif dan signifikan terhadap sikap kreatif pelaku UMKM subsektor ekonomi kreatif di Kecamatan Panakkukang Kota Makassar.
\end{abstract}

Kata Kunci: Pengetahuan kewirausahaan, sikap kreatif, ekonomi kreatif, pendidikan ekonomi

\section{PENDAHULUAN}

Sektor informal memiliki peranan yang cukup strategis dalam pembangunan ekonomi, khususnya dalam mengatasi kemiskinan dan pengangguran. Hal ini berkaitan pula dengan peranan pendidikan ekonomi di sektor informal melalui transformasi nilai dan karakter kewirausahaan dalam aktifitas bisnis atau usahanya. Sektor informal didominasi oleh usaha mikro, kecil dan menengah (UMKM). Beberapa hasil penelitian menunjukkan bahwa pelaku usaha pada sektor informal banyak didominasi oleh pelaku UMKM, baik pada negara sedang berkembang, maupun pada negara maju (Gurtoo dan Williams, 2009; Schneider dan Williams, 2013; Webb et al., 2009; dan Williams, 2009a, b, c, 2010).

Sektor informal tersebut didominasi oleh UMKM. Perkembangan dan kontribusi sector UMKM tidak terlepas dari semakin bertumbuhnya wirausaha-wirausaha baru di masyarakat. Menurut penelitian Bosma, et al., (2011), tren munculnya wirausaha adalah karena tekanan ekonomi, sehingga seseorang terpaksa menciptakan lapangan pekerjaan sendiri. Selain itu ada faktor lain yaitu pengangguran, frustasi pekerjaan sebelumnya, dan kebutuhan hidup layak. Tren perkembangan UMKM di Indonesia saat ini banyak mengarah kepada sektor ekonomi kreatif yang sangat ditentukan oleh modal manusia.

Aset paling penting di era global adalah modal manusia. Suatu bangsa yang memiliki keunggulan komparatif dalam sumber daya alam, tidak akan berbuat banyak dalam kancah persaingan global tanpa didukung oleh keunggulan modal manusia. Hanya bangsa yang unggul dalam modal manusia yang akan dapat berkiprah dan menguasai pengetahuan dan penerapannya dalam wujud nyata pemecah masalah yang dihadapi dalam kehidupan (Thomas, et al., 2013). 
Konsep ekonomi kreatif adalah konsep ekonomi yang didasarkan pada kemampuan dan keterampilan manusia. Hal ini sesuai dengan pernyataan pernyataan (Toffler, 1970), secara keseluruhan, Toffler membagi peradaban manusia menjadi tiga gelombang ekonomi. Pergeseran paradigma dalam pembangunan ekonomi tidak bisa dipisahkan dengan perubahan skala global. Perubahan tersebut ditandai oleh pergeseran pembangunan ekonomi dari sektor pertanian, industri, dan informasi ke sektor ekonomi kreatif. Perkembangan sektor ekonomi kreatif suatu bangsa akan bersaing dan berdampak pada kehidupan sosial jika dikelola dengan baik. Oleh karena itu, bangkitnya gelombang ekonomi baru menuntut inovasi dan kreativitas masyarakat, sehingga dibutuhkan kualitas sumber daya manusia sebagai pelaku ekonomi kreatif. Kondisi ini harus dikaitkan dengan kemampuan dalam mengelola potensi. Oleh karena itu, konsep ekonomi kreatif harus sesuai dengan kemampuan inovasi dan kreativitas dalam mengelola potensi lokal yang ada (Peters, 2004).

Perkembangan ekonomi kreatif tidak terlepas dari perkembangan industri kreatif karena pengembangan ekonomi kreatif membutuhkan dukungan dari industri ekonomi. Perkembangan ekonomi kreatif diyakini sebagai cara bagi negara berkembang untuk mengikuti perkembangan ekonomi global. Hal ini karena sektor ekonomi kreatif lebih mengandalkan kreativitas dan intelektual masyarakat dalam mengembangkan potensi lokal yang ada. Di sisi lain, pengembangan ekonomi kreatif di tempat tertentu sangat bergantung pada kualitas sumber daya manusia dalam mengembangkan kreativitas suatu kecerdasan. Dengan kata lain, pengembangan ekonomi kreatif merupakan kegiatan ekonomi alternatif bagi masyarakat dalam mengembangkan potensinya (UNDP, 2013).

Penjelasan tersebut dapat menunjukkan bahwa perubahan ekonomi ditentukan oleh kualitas sumber daya manusia dalam menggali kreativitas sebagai inovasi sebagai dorongan utama dalam mengembangkan ekonomi kreatif. Karena itu, jika masyarakat memiliki inovasi dan kreativitas, percepatan pembangunan ekonomi akan semakin cepat. Oleh karena itu, pilihan dalam pengembangan ekonomi kreatif akan meningkatkan bisnis yang kompetitif (De Natale dan Wassal, 2006). Perkembangan sektor ekonomi kreatif juga harus berorientasi pada aspek budaya masyarakat. Oleh karena itu, perkembangan sektor ekonomi menguntungkan akan berdampak pada bangkitnya peluang bisnis yang digerakkan oleh masyarakat (Florida, 2006). Oleh karena itu pembangunan yang terstruktur dan sistematis akan mendorong pengembangan sektor ini di daerah. Menurut penjelasan itu menunjukkan bahwa kreativitas yang timbul dari kekayaan budaya akan menciptakan lapangan kerja. Oleh karena itu, dengan berkembangnya ekonomi kreatif maka akan meningkatkan pendapatan masyarakat (Hamilton, et al., 2009), (Cunningham dan Higgs, 2008).

Salah satu Kecamatan di Kota Makassar yang identik dengan ekonomi kreatif adalah Kecamatan Panakkukang. Kecamatan Panakkukang merupakan pusat kawasan ekonomi kreatif Kota Makassar. Dengan berbagai potensi yang dimiliki, seperti banyaknya hotel yang siap menampung para wisatawan, juga mall dan pasar-pasar sebagai lokasi strategis untuk memasarkan produk kreatif, menjadi kekuatan tersendiri bagi Kecamatan Panakkukang dalam pemberdayaan ekonomi masyarakat melalui program pembinaan ekonomi kreatif. Pada Kecamatan Panakkukang terdapat 71 hotel yang siap menjadi sarana penunjang bagi pemasaran produk-produk kreatif, sehingga dapat terbangun citra positif bagi Kecamatan Panakkukang melalui sarana pariwisata. Pada Kecamatan Panakkukang terdapat 129 Zona kreatif pada tahun 2016.

Tabel 1. Data Zona Kreatif Tahun 2016

\begin{tabular}{lc}
\hline Subsektor Industri Kreatif yang digeluti & Jumlah Pelaku Usaha \\
\hline Desain interior & 5 \\
Pakaian & 55 \\
Seni rupa & 28 \\
Seni pertunjukan & 1 \\
Penerbitan dan percetakan & 4 \\
Kuliner & 36 \\
\hline Jumlah & 129 \\
\hline
\end{tabular}

Sumber: Zona Kreatif Kecamatan Panakkukang Tahun 2016 
Kecamatan Panakkukang sangat berpotensi untuk memasarkan produk-produk kreatif Makassar. Terutama Batik khas Sulawesi Selatan yang dinamakan Batik Lontara dan Batik Makassar yang mempunyai berbagai macam motif seperti motif Toraja, Bugis, Makassar, Maros, Pare-Pare, dan Soppeng. Selain batik ada pula baju kebaya dan baju payet khas Makassar, sarung sutera Bugis yang terkenal, kaos kareba dan tenun Sengkang, serta industri batik bisa kita temukan di Kecamatan Panakkukang.

Fakta empirik menunjukan bahwa mayoritas produk-produk kreatif di Kecamatan Panakkukang dihasilkan oleh UMKM yang masuk dalam kategori informal. UMKM sektor informal tersebut masih memiliki beberapa masalah, beberapa masalah tersebut antara lain meliputi rendahnya aspek kreatifitas dan inovasi yang dimiliki karena kurangnya pengetahuan. Rendahnya sikap kreatif berakibat pada rendahnya sikap inovatif, motivasi berprestasi, berorintasi pada laba, ketekunan dan ketabahan, tekad kerja keras, mempunyai dorongan kuat, energik, dan berinisiatif

Aspek pengetahuan merupakan salah hal yang penting di era ekonomi kreatif. Hasil penelitian Hasan (2012) terkait karakteristik tenaga kerja industri kecil menunjukan bahwa tenaga kerja pada industri kecil di Kota Makassar, memiliki karakteristik memanfaatkan pengetahuan ekonomi yang mereka miliki, baik yang diperoleh secara formal maupun informal dalam melakukan kegiatan produksi. Temuan lain dari Hasan (2014) terkait produktivitas dan elastisitas kesempatan kerja sektor industri menunjukan bahwa pengetahuan serta pendidikan merupakan salah satu aspek yang sangat penting dalam menentukan perilaku ekonomi khususnya yang terkait dengan kesempatan kerja dan keputusan-keputusan ekonomi lainnya.

Berdasarkan hal tersebut, pembinaan ekonomi kreatif dalam perspektif pendidikan ekonomi merupakan kajian yang perlu untuk dilakukan karena pendidikan ekonomi merupakan salah satu upaya untuk membina ekonomi kreatif di Kecamatan Panakukkang. Pembinaan ekonomi kreatif dalam perspektif pendidikan ekonomi dilakukan dalam bentuk transfer pengetahuan, baik secara formal, nonformal, maupun informal. Pengetahuan yang ditransfer sebagai upaya untuk meningkatkan inovasi dan kreatifitas UMKM yang bergerak dalam bidang ekonomi kreatif dibedakan menjadi dua, yaitu tacit dan eksplisit (Nonaka et al., 1995; Polanyi, 1966; Spender, 1995). Karakter pengetahuan tacit menurut Polanyi (1966) dikonstruksi dari pengalaman individual dan merupakan bentuk dasar dari pengetahuan eksplisit. Pengetahuan tacit merepresentasikan pengetahuan yang dimiliki oleh seseorang, melekat pada pikiran, dan tidak bisa dipisahkan dari orang yang memilikinya. Sebagai konsekuensinya, pengetahuan tacit sulit untuk ditransfer (Nonaka et al., 1995). Pengetahuan eksplisit adalah pengetahuan yang mudah diubah dalam bentuk formal dan bahasa yang sistematis sehingga lebih mudah ditransfer daripada pengetahuan tacit (Nonaka et al., 1995).

Berdasarkan hal tersebut, dapat dinyatakan bahwa transfer pengetahuan dalam pembinaan ekonomi kreatif yang dilakukan terwujud dalam aspek pengetahuan kewirausahaan yang berhubungan dengan sikap kreatif. Pengetahuan kewirausahaan merujuk pada Meredith (2005), yang terdiri dari variabel pengetahuan berwirausaha dengan indikatornya adalah pengetahuan perencanaan usaha, pengetahuan pengambilan keputusan, pengetahuan mengelola perusahaan, pengetahuan mengatur keuangan, pengetahuan teknik/proses produksi, pengetahuan merancang produk, pengetahuan teknik memasarkan, pengetahuan mendistribusikan barang, pengetahuan administrasi pembukuan, pengetahuan teknik mengendalikan perusahaan.

Sedangkan variabel sikap kreatif, merujuk kepada teori tingkat kreativitas dari Mc Gregor (2007) merupakan dimensi proses kreatif yang indikatornya adalah kelancaran dalam berpikir, keorsinilan dalam berpikir serta kelenturan dalam berpikir. Berdasarkan hal tersebut, maka hipotesis penelitian ini adalah pengetahuan berwirausaha berpengaruh positif terhadap sikap kreatif.

\section{METODE}

Penelitian ini adalah penelitian kuantitatif. Data yang digunakan dalam penelitian ini bersumber dari pelaku UMKM subsektor industri keratif di Kota Makassar. Adapun jenis data dalam penelitian ini meliputi data primer dan data sekunder. Data primer diperoleh melalui penyebaran kuesioner dan wawancara langsung dengan responden mengenai pendidikan ekonomi dan pembinaan ekonomi kreatif, khususnya yang terkait dengan variabel pengetahuan kewirausahaan dan sikap kreatif. Sedangkan data sekunder diperoleh dari 
Badan Ekonomi Kreatif, yaitu berupa jumlah dan sebaran UMKM subsector ekonomi kreatif di Kecamatan Panakkukang serta data dalam bentuk dokumentasi lainnya yang berkaitan dengan masalah penelitian.

Populasi dalam penelitian ini adalah keseluruhan pelaku usaha yang menggeluti bidang ekonomi kreatif di Kecamatan Panakkukang sebanyak 129 pelaku UMKM subsektor industri kreatif. Pengambilan sampel ditentukan dengan menggunakan teknik purposive sampling, tujuannya untuk menjaring sampel yang benar-benar representatif dengan penelitian, sehingga diperoleh sebanyak 33 pelaku usaha UMKM subsektor industri kreatif di Kecamatan Panakkukang. Teknik analisis data yang digunakan dalam penelitian ini adalah regresi linier berganda melalui program SPSS versi 21.

Tabel 1. Hasil Estimasi

\section{HASIL DAN PEMBAHASAN}

Ringkasan hasil penelitian dapat dilihat pada Tabel 1. Berdasarkan hasil pengolahan data melalui Program SPSS Versi 21 diperoleh hasil persamaan regresi $\mathrm{Y}=2,861+7,199 \mathrm{X}_{1}+\mathrm{e}$. Persamaan ini menunjukan pengetahuan kewirausahaan mempunyai pengaruh yang positif terhadap sikap kreatif. Hal tersebut berarti bahwa apabila pengetahuan meningkat, juga akan semakin meningkatkan sikap kreatif. Kontribusi pengetahuan kewirausahaan terhadap sikap kreatif pelaku UMKM subsektor industri kreatif di Kota Makassar adalah sebesar 54,2 persen, sedangkan sisanya 45,8 merupakan kontribusi variabel lainnya yang tidak dimasukkan ke dalam model penelitian.

\begin{tabular}{lcccc}
\hline \multicolumn{1}{c}{$\begin{array}{c}\text { Variabel Bebas dan } \\
\text { Konstanta }\end{array}$} & $\begin{array}{c}\text { Koefisien } \\
\text { Regresi }\end{array}$ & $\begin{array}{c}\text { Standard of } \\
\text { Error }\end{array}$ & thitung $_{\text {hignifikansi }}$ & Signas \\
\hline Konstanta & 2,861 & 5,371 & 1,701 & 0,041 \\
Pengetahuan Kewirausahaan & 7,199 & 0,142 & 5,504 & 0,001 \\
\hline *Taraf kepercayaan $\alpha=5 \%$ & & & & \\
R Square $=0,542$ & & & & \\
\hline
\end{tabular}

Hasil uji signifikasi melalui uji t dengan menggunakan Program SPSS Versi 21 dapat dilihat pada Tabel 2. Hasil pengolahan data menunjukan bahwa pengetahuan kewirausahaan mempunyai pengaruh yang signifikan terhadap sikap kreatif pelaku UMKM subsektor industri kreatif di Kota Makassar.

Tabel 2. Uji Signifikansi

\begin{tabular}{lcccc}
\hline \multicolumn{1}{c}{ Variabel Bebas } & $\mathbf{t}_{\text {hitung }}$ & Signifikansi & $\begin{array}{c}\text { Taraf } \\
\text { Signifikan }\end{array}$ & Kesimpulan \\
\hline Konstanta & 1,701 & 0,041 & 0,05 & Signifikan \\
Pengetahuan Kewirausahaan & 5,504 & 0,001 & 0,05 & Signifikan \\
\hline
\end{tabular}

Temuan penelitian ini menunjukkan bahwa pengetahuan kewirausahaan mempunyai pengaruh yang signifikan terhadap sikap kreatif pelaku UMKM subsektor industri kreatif di Kota Makassar. Pengetahuan kewirausahaan mengacu pada apresiasi individu terhadap konsep, keterampilan dan mentalitas yang diharapkan dari seorang wirausahawan (Jack \& Anderson, 1999). Massad dan Tucker (2009) mengartikulasikan bahwa pengetahuan ini dapat diperoleh dan dikembangkan melalui aktivitas kewiraswastaan, yang dalam hal ini merupakan aktifitas kewirausahaan yang dilakukan oleh pelaku UMKM subsektor industri kreatif di Kota Makassar. Temuan penelitian ini sejalan dengan Turker (2009) mengidentifikasi jenis pengetahuan kewiraswastaan yang saling melengkapi dalam menghasilkan sikap kreatif. Jenis pengetahuan tersebut berhubungan dengan kemampuan individu untuk mengenali peluang kewirausahaan yang melibatka penemuan dan inovasi.

Kemampuan UMKM subsektor industri kreatif di Kota Makassar untuk mencapai keberhasilan tertentu di antaranya dipengaruhi oleh faktor kewirausahaan. Implikasi dari penerapan konsep kewirausahaan itu sendiri dalam organisasi bisnis dinyatakan bahwa apabila pengusaha ingin berhasil dalam menghadapi persaingan yang terbuka dalam era global saat ini harus memiliki jiwa kewirausahaan yang kreatif dan inovatif, terlebih 
melihat kondisi saat ini tentu diperlukan wirausaha yang modern, yang lebih memiliki wawasan, berpikiran jauh ke depan, senantiasa mengikuti perkembangan, terbuka terhadap konsep dan ide baru. Dengan pandangan yang jauh ke depan, selalu berkarya dan berkarsa, menciptakan sesuatu yang baru, terbuka terhadap pengalaman yang baru, termasuk tidak puas dengan apa yang dilakukan saat ini merupakan sisi keberhasilan dalam menjalankan aktivitas bisnisnya tersebut yang terkait dengan kompetensinya. Penentu keberhasilan tersebut adalah kompetensi kewirausahaan yang dalam hal ini kreativitas maupun inovasi sebagai penentu yang merupakan ciri wirausaha yang diimplikasikan dari pengetahuan kewirausahaan yang diperoleh.

Sehubungan dengan keterkaitannya dengan pengetahuan kewirausahaan, sikap kreatif merupakan penyatuan pengetahuan dari berbagai bidang pengalaman berlainan untuk menghasilkan ide-ide baru dan lebih baik. Kreativitas juga sebagai penghasil ide baru dan inovasi sebagai penerjemah ide baru menjadi perusahaan baru, produk baru, jasa baru, proses baru atau metode baru untuk memproduksi (Stoner, Freeman dan Gilbert,1995). Temuan penelitian yang menunjukan terdapatnya pengaruh antara pengetahuan kewirausahaan terhadap sikap kreatif ini sejalan dengan beberapa literatur dan penelitian sebelumnya. Sikap kreatif merupakan inti dari pengetahuan kewirausahaan (Wood and McKinley, 2010). Wirausaha yang kreatif akan senantiasa bekerja keras dan terus menerus untuk memperbaiki gagasan dan solusi, dengan melakukan perubahan dan penyempurnaan bertahap terhadap karya mereka.

\section{SIMPULAN DAN SARAN}

Hasil penelitian menunjukan bahwa pengetahuan kewirausahaan mempunyai pengaruh yang signifikan terhadap sikap kreatif pelaku UMKM subsektor industri kreatif di Kota Makassar. Hasil penelitian ini berimplikasi pada pembinaan pelaku UMKM subsektor industri kreatif di Kota Makassar perlu untuk mempertimbangan aspek pendidikan kewirausahaan, baik formal, nonformal, informal, sehingga melalui pendidikan tersebut terbentuk pengetahuan kewirausahaan. Melalui pengetahuan tersebut diharapkan agar sikap kreatif dapat terbentuk untuk mewujudkan kesuksesan bisnis pelaku UMKM subsektor industri kreatif di Kota Makassar.

\section{DAFTAR RUJUKAN}

Cunningham, Stuart D. and Higgs, Peter L. 2008. Creative industries mapping: where have we come from and where are we Going?, Creative Industries Journal, 1(1). pp. 18-22.

De Natale, D.and Wassall, GH. 2006. Creative economy research in New England: A reexamination white paper prepared for discussion at the Research Convening of the New England Research Community March 27, 2006, New England Foundation for the Arts, Northeastern Universit, New England Foundation for the Arts www.nefa.org, p.5-13

Florida, R. 2006. The flight of the creative class: the new global competition for Talent, Summer 2006, Harper Business. www.creativeclass.org, p.22

Gurtoo, A. \& Williams, C. C. 2009. Entrepreneurship and the informal sector: some lessons from India. International Journal of Entrepreneurship and Innovation, $\quad 10, \quad 55-62$. http://dx.doi.org/10.5367/0000000097874 14280.

Hamilton L. et.al. 2009. Building the creative economy in Nova Scotia. The Research Committee of The Nova Scotia Cultural Action

Network. www.NovaScotiaCAN.ca, (p. 27-12)

Hasan, Muhammad. 2012. Karakteristik tenaga kerja industri kecil. Jurnal Ekonomi Pembangunan dan Pertanian Volume 2, No. 1 November 2012 ISSN 2252-4678. Makassar: Program Studi Ekonomi Pembangunan FE UNM.

Hasan, Muhammad. 2014. Produktivitas dan elastisitas kesempatan kerja sektor industri. Jurnal Economix Volume 2, No. 1 Desember 2014 ISSN 2302-6286. Makassar: Fakultas Ekonomi UNM.

Jack, Alistair R. Anderson. 1999. Entrepreneurship education within the enterprise culture: Producing reflective practitioners. International Journal of Entrepreneurial Behavior \& Research, Vol. 5 Issue: 3, pp.110-125.

McGregor, D. 2007. Thinking: developing learning. A guide to thinking skills in 
education. McGrawHill: Open University Press.

Meredith G, Geoffrey et al. 2005. Kewirausahaan teori dan praktek (Penerjemah: Andre Asparsayogi). Jakarta: Pustaka Binaman Pressindo.

Nonaka, I., \& Takeuchi, H. 1995. The knowledge - creating company. New York: Oxford University Press.

Peters, Michael A. 2004. Education and ideologies of the knowledge economy : Europe and Politics of Emulation, Social Work \& Society, Volume 2, Issues 2. http//socwork.net/peters2004.pdf, p 162164.

Polanyi, M. 1966. The tacit dimension. New York: Anchor Day.

Schneider, F. \& Williams, C. C. 2013. The shadow economy. London: Institute of Economic Affairs. http://dx.doi.org/10.1017/CBO978113954 2289.

Spender, J. C. 1996. Making knowledge the basis of a dynamic theory of the firm. Strategic Management Journal, 17 (Knowledge and The Firm), 45-62.

Stoner, A, Freeman, E \& Gilbert, D. 1995. Management, Sixth edition. New York: Prentice Hall.

Thomas, H., Smith, R.R. and Diez, F. 2013. Human capital and global business strategy. New York: Cambridge University Press.

Toffler, Alvin. 1970. Future shock. New York: Random House.

United Nations Development Programme (UNDP). 2013. Creative economy report, widening local development pathways, New York, NY 10017, USA and the
United Nations Educational, Scientific and Cultural Organization (UNESCO), 7 , p.17.ISBN 978-92-3-001211.

Webb, J. W., Tihanyi, L., Ireland, R. D. \& Sirmon, D. G. 2009. You say illegal, I say legitimate: entrepreneurship in the informal economy. Academy of Management Review, 34, 492-510. http://dx.doi.org/10.5465/AMR.2009.4063 2826.

Williams, C. C. 2009a. Entrepreneurship and the off-the-books economy: some lessons from England. International Journal of Management and Enterprise Development, 7, 429-444. http://dx.doi.org/10.1504/IJMED.2009.02 6308.

Williams, C. C. 2009b. The motives of off-thebooks entrepreneurs: necessity- or opportunity-driven?. International Entrepreneurship and Management Journal, 5, 203-217. http://dx.doi.org/10.1007/s11365-0080098-8.

Williams, C. C. 2009c. The hidden enterprise culture: entrepreneurs in the underground economy in England, Ukraine and Russia. Journal of Applied Management and Entrepreneurship, 14, 44-60.

Williams, C. C. 2010. Spatial variations in the hidden enterprise culture: some lessons from England. Entrepreneurship and Regional Development, 22, 403-423. http://dx.doi.org/10.1080/0898562090316 8281.

Wood, M. and W. McKinley. 2010. The production of entrepreneurial opportunity: A constructivist perspective, Strategic Entrepreneurship Journal 4(1): 66-84. 